\title{
Content Analysis of the Discussion of the Atom in General Chemistry Texthooks Using Evaluation Criteria Based on the Nature of Science and Philosophy of Chemistry
}

\author{
Angelo Julian E. Perez ${ }^{1 *}$, Armando M. Guidote, Jr. ${ }^{2}$, Gilbert U. Yu², Michael Ner E. \\ Mariano $^{3}$ \\ ${ }^{1}$ Science Department, Senior High School - IB Diploma Program, Xavier School, San Juan City \\ ${ }^{2}$ Department of Chemistry, School of Science and Engineering, Ateneo de Manila University, Quezon City \\ ${ }^{3}$ Department of Philosophy, School of Humanities, Ateneo de Manila University, Quezon City
}

\begin{abstract}
Evaluation criteria are adapted from previous textbook analyses on the nature of science (NOS) in general chemistry textbooks. These criteria are used to determine how certain NOS dimensions are mentioned and elaborated in those textbooks. Such dimensions emphasize that chemistry is (1) tentative, (2) empirical, (3) model-based, (4) inferential, (5) has technological products, (6) employs instrumentation, and (7) possesses social and societal dimensions. Three book chapters were read and evaluated: the first (on chemistry in general); the second (on atomic structure); and the sixth or seventh chapters (on the electronic structure of atoms). The relevant content in each textbook were rated using the following rubric: Satisfactory and Explicit (S, 2 points); Mention and Implicit ( $M$, 1 point); and No Mention ( $N$, 0 point). Silberberg (2009) has the highest score among the six textbooks with 12 points out of the maximum of 14 . It was rated $S$ for five criteria, the most among the six textbooks. Despite the presence of some $N$ evaluations, all textbooks have mentioned some or all of the NOS dimensions formulated, resulting to $M$ and $S$ ratings. This study concludes that NOS dimensions are already present in various ways and varying degrees in each textbook.
\end{abstract}

Keywords: History and Philosophy of Science; Philosophy of Chemistry; Nature of Science; Chemistry Education; Textbook Analysis; General Chemistry

\section{INTRODUCTION AND REVIEW OF LITERATURE}

This study is at the intersection of chemistry, philosophy and education. There has been literature arguing for the need to apply insights from the history and philosophy of science (HPS) to science education. HPSbased research as applied to science education can enrich and challenge the sciences. Matthews (2001) claims that HPS can: "humanize the sciences and connect them to personal, ethical, cultural, and political concerns; enhance reasoning and critical 
thinking skills; contribute to the fuller understanding of scientific subject matter; improve teacher education by assisting teachers to develop a richer and more authentic understanding of science; contribute to the clearer appraisal of many contemporary educational debates that engage science teachers and curriculum planners" (p. 11). At its core however, HPS asks a basic question: "What is this thing we call science?" This simple but central question leads to other hosts of questions, such as: "How is science a human and social endeavor?" What does it mean to 'do' science?" and "How does scientific knowledge differ from other kinds of knowledge?" As such, HPS moves beyond the laboratory setting, as well as scientists' own views of their field, to consider other ways of thinking and knowing that might inconspicuously impinge upon the scientific endeavor. Under HPS-based research is discussion on the nature of science (NOS). NOS research involves questions such as "what science is, how it works, how scientists operate as a social group and how society itself both directs and reacts to scientific endeavors" (McComas et al., 1998). As such, NOS challenges misconceptions and myths, people, including science educators and students, might have about science.

This study also considers the emerging field of philosophy of chemistry, the academic intersection between standard philosophy of science and the scientific discipline of chemistry. The Stanford Encyclopedia of Philosopby defines two sets of issues and questions that philosophy of chemistry engages in: (a) conceptual issues unique in chemistry, in which they are clarified, articulated and analyzed (e.g. the nature of substance, atomism, the chemical bond, and synthesis). Such issues are subjected to philosophical rigor and perspectives; and (b) re-exploration of traditional topics in the philosophy of science specifically within the context of chemistry (e.g. realism, reduction, explanation, modeling, confirmation). These standard topics are discussed in view of specific chemistry examples and applications. (cf. Weisberg et al., 2011)
Philosophy of chemistry could help students and teachers gain a deeper understanding of the nature of chemistry. The article "Chemistry Education: Ten Facets to Shape Us" by Vicente Talanquer (2013) in the Journal of Chemical Education mentions ten recent reconceptualizations and new perspectives (which he calls facets) on how chemistry teachers and students could better synthesize and make sense of chemical knowledge taught in the classroom. He calls his ninth facet as Philosophical Considerations, in which philosophy of chemistry is mentioned. Talanquer (2013) argues that issues and debates in philosophy of chemistry could help students and teachers be aware of the power, scope, as well as the limitations of concepts, laws and models we use in chemistry; utilize philosophical arguments as pedagogical tools; gain a much deeper understanding of the nature of chemistry; and be critically reflective of chemistry itself.

A further line of study in science education consists of content analyses of textbooks based on their degree and quality of presentation of certain NOS dimensions. Many studies on the HPS and NOS are cognizant of "the role played by textbooks in developing students' informed NOS conceptions....Recent HPS-based research has shown increasing interest in analyzing textbooks and thus providing guidelines for future textbooks" (Niaz and Maza, 2011, p. 2). Chapter 44 of the International Handbook of Research in History, Philosophy and Science Teaching, authored by Mansoor Niaz (2014), reviews the current literature on evaluating and consequently suggesting the inclusion of HPS perspectives in science textbooks. These studies in promoting HPS perspectives in science education argue that HPS and NOS should not be an extra, but instead infused in various modes of learning in science education, including textbooks. Another study concurs, saying that " $[\mathrm{t}]$ extbooks, as one of the most important science teaching resources, should provide teachers with a sufficiently wide variety of examples to discuss the different dimensions of NOS" (Vesterinen et al., 2013, p. 1851). This area of science 
education research has the same motivation as that of Talanquer (2013) mentioned above - a moving away from conventional, even outmoded, ways of presenting and explaining scientific knowledge. Niaz (2014) further notes that under textbook analysis research, there are two types of studies presently done that entail evaluation of textbooks (p. 1413): (1) domain specific ["based on a historical reconstruction of a given topic of the science curriculum"]; and (2) domain general ["based on a series of nature of science (NOS) dimensions, which are in turn derived from the history and philosophy of science"]. This present study is of the second type - an evaluation of textbooks based on certain NOS dimensions.

A textbook analysis of Mansoor Niaz and Arelys Maza in 2011 evaluated introductory chapters or prefaces of general chemistry textbooks. They devised nine criteria that elucidated certain elements or dimensions of NOS, some of which include "the tentative nature of scientific theories," that "observations are theory-laden," and that "scientific ideas are affected by their social and historic milieu." The following are the specific guidelines of Niaz and Maza (2011) for their ratings of $S, M$, or $N$, which this present study adopts:

- Satisfactory (S): "Treatment of the subject in the textbook is considered to be satisfactory, if the criterion is described and examples provided to illustrate the different aspects."

- Mention (M): "A simple mention of the criterion with little elaboration and no examples."

- No mention $(N)$ : "No mention of the issues involved in the criterion, as conceived by this study." (p. 9)

The said study also awarded numerical weights to each rating: $S=2, M=1, N=0$. However, while Niaz and Maza's samples are general chemistry textbooks, their NOS criteria are still not specific to chemistry. The chapters that they analyzed (the Introduction, Preface, or first chapters) are also not yet explicit in terms of chemistry concepts.

Thus, another relevant textbook analysis for this present study is that of Vesterinen et al. (2013). This study is particularly significant because it incorporates literature from philosophy of chemistry in its criteria for evaluation of NOS dimensions in chemistry textbooks. Their analysis lies in two successive rounds, each with its own criteria: (1) the four themes of scientific literacy (knowledge of science; investigative nature of science; science as a way of thinking; and interaction of science, technology and society). Focusing on the third theme ("science as a way of thinking”), (2) seven NOS dimensions were developed (tentative; empirical; model-based; inferential; technological products; instrumentation; and social and societal dimensions). Unlike the criteria of Niaz and Maza (2011), the criteria of Vesterinen et al. (2013) are more explicit in terms of chemistry concepts.

These two studies just mentioned, Niaz and Maza (2011) and Vesterinen et al. (2013), would form the backbone for the methodology of the present work. As such, this study aims to specify that link between philosophy of chemistry and chemistry education through textbook analysis. The general objective of this project is to evaluate and analyze select general chemistry textbooks based on their presentation and discussion of the atom using criteria and perspectives from the nature of science and philosophy of chemistry, with the following specific objectives in mind: (a) to formulate criteria for evaluation, adapted from the textbook analyses of Niaz and Maza (2011) and Vesterinen et al. (2013); and (b) to evaluate select (six) college general chemistry textbooks using the above criteria, focusing on how the atom is presented and discussed.

\section{METHODS}

The main aim of this study is to evaluate and analyze select general chemistry textbooks 
based on their discussion of the atom (in particular the discovery and development of theories concerning atomic and electronic structures), using criteria and perspectives from NOS and philosophy of chemistry. As already stated, the textbook analysis for this study appropriates the previous work done by Niaz and Maza (2011) and Vesterinen et al. (2013). In terms of scope, this study also evaluated the first chapters of the textbooks, thus making it similar to Niaz and Maza (2011). However, two additional chapters aside from the preface or introductory chapter were also read and evaluated - those pertaining to the historical development and application of the atomic and quantum theories. Such latter chapters discuss the historical and theoretical development of the concept of the atom - a topic that this study perceives could bring about possible philosophical considerations, as well as corrections to misconceptions that abound in teaching and learning about it. Atoms, as the fundamental unit of matter, can elicit philosophical and critical thinking questions (for instance, the real nature of orbitals, is a key concern in philosophy of chemistry). A more practical reason would be that, due to time constraints and given the focus of this study, this work cannot possibly attempt to evaluate all chapters of each textbook, as done by Vesterinen et al. (2013). While NOS criteria might be expected to be mostly present in the first chapter (due to its more general nature, it focuses more on "science" in general instead of a specific scientific field such as chemistry), this study deems it worthwhile to look at other chapters in the textbook and see how those chapters still have some vestiges of this more general discussion and how they can still carry and discuss the relevant NOS dimensions in specific chemistry topics.

Six textbooks in general chemistry are chosen, all published in the United States, with copies present in the Ateneo de Manila University Department of Chemistry, and used by the department faculty in its undergraduate chemistry courses. The editions under consideration are the most recent ones that are presently available and accessible to the present study. Supplementary Table 1 lists the editions of these general chemistry textbooks, as well as the specific chapters to be analyzed. These textbooks are also widely-known and widely-used titles in university-level general chemistry courses in the Philippines and abroad. There are only three chapters considered and evaluated for this study: the first (which introduces science and chemistry in general); the second (which discusses atoms, molecules and ions, the atomic structure, as well as the development of the atomic theory); and the sixth or seventh chapters (chapters on quantum theory and the electronic structure of atoms, depending on the textbook). Additionally, the Preface is also read to elucidate each author's philosophy on the content and organization of their textbook. Usually, the chapter on the periodic table succeeds the chapter on quantum theory. While these topics are closely related, only the quantum origins of some periodic table properties are considered in this study.

The methodology of this present study closely follows the presentations of Niaz and Maza (2011) and Vesterinen et al. (2013) in their textbook analyses. Since it already involves chemistry and philosophy of chemistry explicitly, the seven-point criteria suggested by Vesterinen et al. (2013) is adapted in this study. So far, it is the only NOS study that explicitly points to literature on the philosophy of chemistry as a source and justification for its criteria. These criteria are as follows: that chemistry is (1) tentative, (2) empirical, (3) model-based, (4) inferential, (5) has technological products, (6) employs instrumentation, and (7) possesses social and societal dimensions. However, there are many overlaps of these present criteria with the previous study of Niaz and Maza (2011), insofar as both studies created evaluation criteria on the nature of science as applied to general chemistry textbooks. The criteria for evaluating general chemistry textbooks were adapted from Vesterinen et al. (2013), but the use of numerical ratings equivalent to No Mention, Mention, or Satisfactory regarding relevant passages were 
taken from Niaz and Maza's study (as mentioned above in the Introduction).

While literature points to textbook analyses already done on the discussion of the atom in textbooks, the novelty of the present work is using the seven-point criteria from Vesterinen et al. (2013) with relevant supplementing information from Niaz and Maza (2011). Vesterinen et al. (2013) did not use a grading scheme. However, one of their tables attributes an Explicit or Implicit label to certain passages. This present study sees the similarities in Niaz and Maza's use of Satisfactory and Vesterinen, et al.'s use of Explicit, as well as No Mention and Implicit, respectively. Hence, these two sets of rubrics are integrated in this study for a set of "hybrid" evaluation criteria. Depending on the quality of exposition and discussion of each NOS dimension, the following points are awarded by this present study to the textbooks being evaluated: Satisfactory and Explicit (S) $=2$ points; Mention and Implicit (M) $=1$ point; No Mention $(\mathrm{N})=0$ point. $\mathrm{A}$ relevant excerpt from the textbook merits a Satisfactory and Explicit grade if it could move beyond mere one-sentence and/or the traditional and usual discussion of the topic at hand, even if the NOS dimension under question is stated. The relevant text should have explicitly included more explanations, illustrations, examples, nuances, and questions that elicit thinking for the students, and it should have informed them of alternative perspectives of looking at the topic at hand. For instance, the usual chemistry major might know and agree that her field is "empirical" and "model-based." However, this study hopes that textbooks (and the chemistry major) move beyond the standard notions of chemistry as "empirical" and "model-based," and instead nuance those terms to accommodate the scope, limitations and other ways of thinking about chemistry concepts.

\section{RESULTS AND DISCUSSION}

Despite the presence of some No Mention $(N)$ evaluations, all textbooks have mentioned some or all of the NOS dimensions formulated, resulting to $M$ and $S$ ratings. Furthermore, it can be seen that the topic of the atom can elicit mention of all of the seven NOS criteria (at least for an $M$ rating). Three textbooks (Brown et al., 2015; Chang, 2010; and Silberberg, 2009) received a mixture of $M$ and $S$ ratings, with no $N$. The other three have received an $N$ rating in some criteria. Of the six textbooks evaluated in this study, Silberberg (2009) received the highest rating (12 points out of a perfect score of 14). Brown et al. (2015) and Hill et al. (2013) closely follow, with 11 and 10 points, respectively.

The results of this study show that NOS dimensions are already present in various ways and varying degrees in each textbook. All textbooks in this study have manifested, in different degrees and combinations, the seven-point criteria used in this study. This confirms an observation made by Niaz (2014): "it is important to note that a small number of textbooks did provide material based on HPS that can further students' understanding of science. This shows that HPS is already 'inside' the science curriculum" (p.1435). The textbooks that merited $S$ ratings are those that gave explicit discussions and/or provided additional text boxes on the NOS dimensions in question. Silberberg (2009), having the highest number of $S$ ratings (5), possesses most of the content (as stated in the sevenpoint criteria) desired by this study.

We know that textbooks form the background of any formal type of education, especially in educational institutions. Hence, there is hope that such dimensions and elements of the "nature of science" could be part of the education of both students and teachers, and more so be discussed in the classroom setting. Agreeing with Niaz and Maza (2011), the relatively high scores of Brown et al. (2015), Hill et al. (2013), and Silberberg (2009) say that while NOS is not an explicit and major objective in chemistry textbooks (so far, no textbook has included the elucidation of NOS as part of its Preface), certain passages inside those textbooks align with NOS dimensions. 
Table 1. Evaluation of Nature of Science in General Chemistry Textbooks $(n=6)$.

\begin{tabular}{|c|c|c|c|c|c|c|c|c|c|}
\hline \multirow{2}{*}{ No. } & \multirow{2}{*}{ Textbook } & \multicolumn{7}{|c|}{ Criteria $^{a}$} & \multirow{2}{*}{ Points $^{\mathrm{b}}$} \\
\hline & & 1 & 2 & 3 & 4 & 5 & 6 & 7 & \\
\hline 1 & $\begin{array}{l}\text { Brown, LeMay, Bursten, } \\
\text { Murphy, Woodward and } \\
\text { Stoltzfus (2015) }\end{array}$ & M & $\mathrm{S}$ & M & $\mathrm{S}$ & M & $\mathrm{S}$ & $\mathrm{S}$ & 11 \\
\hline 2 & Chang (2010) & $\mathrm{M}$ & $\mathrm{M}$ & $\mathrm{M}$ & $\mathrm{M}$ & $\mathrm{M}$ & $\mathrm{S}$ & $\mathrm{M}$ & 8 \\
\hline 3 & $\begin{array}{l}\text { Hill, McCreary and Kolb } \\
\text { (2013) }\end{array}$ & $\mathrm{S}$ & S & S & M & M & $\mathrm{N}$ & $\mathrm{S}$ & 10 \\
\hline 4 & $\begin{array}{l}\text { Masterton, Hurley and Neth } \\
(2012)\end{array}$ & $\mathrm{N}$ & M & M & $\mathrm{N}$ & M & M & $\mathrm{S}$ & 6 \\
\hline 5 & Silberberg (2009) & $\mathrm{M}$ & $\mathrm{S}$ & $\mathrm{S}$ & $\mathrm{S}$ & $\mathrm{M}$ & $\mathrm{S}$ & $\mathrm{S}$ & 12 \\
\hline 6 & Zumdahl and Zumdahl (2014) & $\mathrm{N}$ & $\mathrm{M}$ & $\mathrm{M}$ & $\mathrm{S}$ & $\mathrm{S}$ & $\mathrm{N}$ & $\mathrm{M}$ & 7 \\
\hline
\end{tabular}

Table 1 summarizes the evaluation results of each textbook for all the seven criteria. Specific analyses per criterion are provided below. Due to space constraints, not all excerpts are cited and discussed here. Sample "representative" excerpts having $\mathrm{S}$ and $\mathrm{M}$ ratings are deferred to Supplementary Table 2.

Chemistry is Tentative. Only one textbook received an $S$ rating - Chemistry for Changing Times by Hill et al. (2013), primarily because of the specific and explicit section in its Chapter 1 devoted to the scientific method (Science: Reproducible, Testable, Tentative, Predictive, and Explanatory). Under this section is a subsection entitled "Scientific Theories Are Tentative and Predictive." Excerpt 1.1 in Supplementary Table 2 is from that subsection. The other textbooks have some discussion of the scientific method. However, it is only in Hill et al. (2013) that the word "tentative" is explicitly stated in the context of scientific method. Three textbooks received $M-$ Brown et al. (2015), Chang (2010), and Silberberg (2009). The relevant passage from Brown et al. (2015) is in Supplementary Table 2 (excerpt 1.2), while those from the other two textbooks are shown below. They all hint towards the tentative nature of theories and hypothesis (for instance, that they are not absolutely true and certain), but without making these more explicit.

To be sure, Bohr made a significant contribution to our understanding of atoms, and his suggestion that the energy of an electron in an atom is quantized remains unchallenged. But his theory did not provide a complete description of electronic behavior in atoms. In 1926 the Austrian physicist Erwin Schrödinger, using a complicated mathematical technique, formulated an equation that describes the behavior and energies of submicroscopic particles in general, an equation analogous to Newton's laws of motion for macroscopic objects. The Schrödinger equation requires advanced calculus to solve, and we will not discuss it here. It is important to know, however, that the equation incorporates both particle behavior, in terms of mass $m$, and wave behavior, in terms of a wave function $\psi$ (psi), which depends on the location in space of the system (such as an electron in an atom). [Chang (2010), p. 293, italics in the original]

Whether derived from actual observation or from a "spark of intuition," a hypothesis is a proposal made to explain an observation. A sound hypothesis need not be correct, but it must be testable. Thus, a hypothesis is often the reason for performing an experiment. If the hypothesis is inconsistent with the experimental results, it must be revised or discarded. [Silberberg (2009), p. 13, italics in the original]

Masterton et al. (2012) and Zumdahl and Zumdahl (2014) both received $N$ because they did not have any discussion pertaining to the tentative nature of theories, especially in relation to the scientific method. This study rates the relevant excerpts from Zumdahl and Zumdahl (2014) on the scientific method 
under a different criterion (Criterion 7). They emphasized more the social dimension of the scientific method than its tentative nature. Masterton et al. (2012) did not discuss the scientific method altogether in its Chapter 1.

Chemistry is Empirical. All textbooks have some discussion of the "empirical" criterion, with three textbooks each for the $M$ and $S$ ratings. The three textbooks receiving $S$ do not explicitly state that "chemistry is an empirical science." However, this present study has considered the number of additional content that each textbook gives to experimentation. Since it is standard to teach the development of the atomic and quantum theories, it is expected that all textbooks have some discussion of historical experiments accompanying the various stages of those theories. Vesterinen et al. (2013) also noted in their analysis that for this criterion, "[m] ost of the examples of this dimension are descriptions of historical experiments" (p. 1847). They have also highlighted the interdependency of theory and experiment, and that experimentation is what marks science from other fields.

Three textbooks received $S$ ratings, with excerpts shown below:

Scientists do not merely state what they feel may be true. They develop testable hypothesis (educated guesses) as tentative explanations of observed data. They test these hypotheses by designing and performing experiments. Experimentation distinguishes science from the arts and the humanities. In the humanities, people still argue about some of the same questions that were being debated thousands of years ago: What is truth? What is beauty? These arguments persist because the proposed answers cannot be tested and confirmed objectively. [Hill et al. (2013), p. 5, italics and emphasis in the original]

Hill et al.'s discussion is noteworthy, first because it is under the subsection entitled "Scientific Hypotheses are Testable." Second, in stating that experimentation is what separates the sciences from other fields, it comes very close to the intent of Criterion 2, even without mentioning the word "empirical" explicitly. This is reinforced in their text box What Science is Not, which emphasizes the distinguishing role of experiments in science.

Chemical changes can be dramatic. In the account that follows, Ira Remsen, author of a popular chemistry text published in 1901, describes his first experiences with chemical reactions. The chemical reaction that he observed is shown in Figure 1.11. (Figure 1.11. The chemical reaction between a copper penny and nitric acid. The dissolved copper produces the blue-green solution; the reddish brown gas produced is nitrogen dioxide. While reading a textbook of chemistry, I came upon the statement "nitric acid acts upon copper," and I determined to see what this meant. Having located some nitric acid, I had only to learn what the words "act upon" meant. In the interest of knowledge I was even willing to sacrifice one of the few copper cents then in my possession. I put one of them on the table, opened a bottle labeled "nitric acid," poured some of the liquid on the copper, and prepared to make an observation. But what was this wonderful thing which I beheld? The cent was already changed, and it was no small change either. A greenish-blue liquid foamed and fumed over the cent and over the table. The air became colored dark red. How could I stop this? I tried by picking the cent up and throwing it out the window. I learned another fact: nitric acid acts upon fingers. The pain led to another unpremeditated experiment. I drew my fingers across my trousers and discovered nitric acid acts upon trousers. That was the most impressive experiment I have ever performed. I tell of it even now with interest. It was a revelation to me. Plainly the only way to learn about such remarkable kinds of action is to see the results, to experiment, to work in the laboratory.) [Brown et al. (2015), pp. 12-13]

Brown et al. (2015) cited that interesting anecdote to show that certain chemical properties could only be observed through experiment. Aside from that excerpt, the authors also have two text boxes relevant for Criterion 2 - Measurement and the Uncertainty Principle, and Design an Experiment on the photoelectric effect. Aside from an explicit discussion of what a scientific experiment is (excerpt 2.1 in Supplementary Table 2), Silberberg (2009) has another relevant passage 
that explains the important role of quantitative and reproducible measurements in science. The following is an excerpt from Silberberg's discussion of Lavoisier and how careful measurements led this scientist to develop his own theory of combustion.

Lavoisier's new theory of combustion made sense of the earlier confusion. A combustible substance such as charcoal stops burning in a closed vessel once it combines with all the available oxygen, and a metal oxide weighs more than the metal because it contains the added mass of oxygen. This theory triumphed because it relied on quantitative, reproducible measurements, not on the strange properties of undetectable substances. Because this approach is at the heart of science, many propose that the science of chemistry began with Lavoisier. [Silberberg (2009), p. 12, italics in the original]

As mentioned, the remaining three textbooks all received $M$ ratings. They have discussed the connection between theory and experiment in some way, however lacking the elaboration and creativity of the discussions above. Excerpt 2.2 in Supplementary Table 2 is from Zumdahl and Zumdahl (2014). Passages from the other two textbooks are cited below:

Hypotheses that survive many experimental tests of their validity may evolve into theories. A theory is a unifying principle that explains a body of facts and/or those laws that are based on them. Theories, too, are constantly being tested. If a theory is disproved by experiment, then it must be discarded or modified so that it becomes consistent with experimental observations. Proving or disproving a theory can take years, even centuries, in part because the necessary technology may not be available. [Chang (2010), p. 9, italics and emphasis in the original]

Like any useful scientific theory, the atomic theory [of Dalton] raised more questions than it answered. Scientists wondered whether atoms, tiny as they are, could be broken down into still smaller particles. Nearly 100 years passed before the existence of subatomic particles was confirmed by experiment. Two future Nobel laureates did pioneer work in this area. J. J. Thomson was an English physicist working at the Cavendish Laboratory at Cambridge. Ernest Rutherford, at one time a student of Thomson's, was a native of New Zealand. Rutherford carried out his research at McGill University in Montreal and at Manchester and Cambridge in England. He was clearly the greatest experimental physicist of his time, and one of the greatest of all time. [Masterton et al. (2012), p. 28]

Chemistry is Model-Based. As with Criterion 2, all textbooks have some discussion of the "model-based" criterion, thus no textbook received an $N$ rating; four received $M$ ratings, and only Hill et al. (2013) and Silberberg (2009) receiving S. All textbooks have some discussion of models and specific models accompanying specific areas and historical periods in chemistry. To qualify for the $S$ rating however, this study looked at how models as such are explicitly discussed in each textbook's discussion of the scientific method. Those who received $S$ ratings either have explicit subsections discussing models and/or have devoted several paragraphs explaining what models do for science. Silberberg's excerpt is 3.1 in Supplementary Table 2, stating that the creation of models is an important aim for the scientific method. Silberberg's introduction to his chapter on quantum theory is also noteworthy in its summary of several competing models:

$[\mathrm{R}]$ evolutions in science are not the violent upheavals of political overthrow. Rather, flaws appear in an established model as conflicting evidence mounts, a startling discovery or two widens the flaws into cracks, and the conceptual structure crumbles gradually from its inconsistencies. New insight, verified by experiment, then guides the building of a model more consistent with reality. So it was when Lavoisier's theory of combustion superseded the phlogiston model, when Dalton's atomic theory established the idea of individual units of matter, and when Rutherford's nuclear model substituted atoms with rich internal structure for "billiard balls" or "plum puddings." In this chapter, you will see this process unfold again with the development of modern atomic theory. [Silberberg (2009), p. 269] 
The following excerpt is from Hill et al. (2013):

Scientists use models to help explain complicated phenomena. A scientific model uses tangible items or pictures to represent invisible processes. For example, the invisible particles of a gas can be visualized as billiard balls, as marbles, or as dots or circles on paper. We know that when a glass of water is left standing for a period of time, the water disappears through the process of evaporation. Scientists explain evaporation with a theory, the kinetic-molecular theory, which proposes that a liquid composed of tiny particles called molecules that are in constant motion....In the bulk of the liquid, these molecules are held together by forces of attraction. The molecules collide with one another like billiard balls on a playing table. Sometimes, a "hard break" of billiard balls causes one ball to fly off the table. Likewise, some of the molecules of a liquid gain enough energy through collisions to break the attraction to their neighbors, escape from the liquid, and disperse among the widely spaced molecules in air. The water in the glass gradually disappears. This model gives us more than a name for evaporation; it gives us an understanding of the phenomenon. [Hill et al. (2013), p. 6, italics in the original]

Aside from the above passage is taken from the subsection "Scientific Models are Explanatory." Another noteworthy passage is its tabulated version of the postulates under Dalton's atomic theory vis-à-vis modern modifications of it, the only textbook to have done so.

In turn, the other four textbooks receiving $M$ ratings only described particular models, however still carrying the notion that models replace older models depending on the available experimental evidence. Excerpt 3.2 in Supplementary Table 2 is from Masterton et al. (2012), while the passage below is from Chang (2010):

This was a most surprising finding [Rutherford's alpha particle experiments] for, in Thomson's model, the positive charge of the atom was so diffused that the alpha particles were expected to pass through with very little deflection... Rutherford was later able to explain the results of the scattering experiment, but he had to abandon Thomson's idea and propose a new model for the atom. [Chang (2010), p. 47]

While Zumdahl and Zumdahl (2014) has an explicit subsection entitled "Scientific Models" (in its Chapter 1), the pertinent paragraph discussing the model is not that explicit, compared with Silberberg's and Hill et al.'s, as shown above. It only focused on the notion of models as human constructs.

Chemistry is Inferential. For this criterion, attention was focused on two sets of discussions: (1) on chemistry as the science that bridges (through inference) the submicroscopic and macroscopic realms, and (2) how scientists actually use inference when they think and work. If the textbooks have at least excerpts pertaining to the first, then they are graded as $M$. Chang (2010), excerpt 4.2 in Supplementary Table 2, is rated in this way because it only has the first set of relevant points.

Three textbooks rated as $S$ (Brown et al., 2015; Silberberg, 2009; and Zumdahl and Zumdahl, 2014) all have discussions of the microscopic and macroscopic realms in chemistry, but they also provided additional relevant excerpts pertaining to the second set of expected discussion mentioned above. They have passages on the scientific method as not fixed and requiring much inference and creativity. Zumdahl and Zumdahl (2014) is cited as excerpt 4.1 of Supplementary Table 2.

Lastly, there are two textbooks that do not have the first set of expected content Masterton et al. (2012), and Hill et al. (2013). The former is rated as $N$ for Criterion 4. As for Hill et al. (2013), this study decided to rate it as $M$ because it has many passages that pertain to the second set of expected content. One such passage is as follows:

Atoms are exceedingly tiny particles, much too small to see even with an optical microscope. It is true that scientists can obtain images of individual atoms, but they use special instruments such as the scanning tunneling microscope. Even so, we can see only 
outlines of atoms and their arrangements in a substance. If atoms are small, how can we possibly know anything about their inner structures? Although scientists have never examined the interior of an atom directly, they have been able to obtain a great deal of indirect information. By designing clever experiments and exercises their powers of deduction, scientists have constructed an amazingly detailed model of what an atom's interior must be like. [Hill et al. (2013), p. 61, italics in the original]

Aside from that passage, it has sections on critical thinking and serendipity, respectively. Unfortunately, it has no relevant passage explaining the role of chemistry as bridging the submicroscopic and macroscopic realms.

\section{Chemistry has Technological Products.} The evaluation of Criterion 5 poses a problem for this study because the textbook chapters under consideration are not explicitly on chemical reactions, synthesis, or organic chemistry. Those chapters will naturally have mentioned newly discovered or synthesized compounds. In contrast, the chapters evaluated here deal mostly with the general nature of science and chemistry, as well the historical development of atomic and quantum theories. Nevertheless, Criterion 5 is retained in this study to be complete and consistent with the application of the criteria from Vesterinen et al. (2013).

For the purposes of this study, technological products pertain not only to the synthesis of compounds, but also to any discussion (in the chapters under evaluation) of any products or materials whose properties could be explained by understanding the concepts in those chapters. Only Zumdahl and Zumdahl (2014) received an $S$ rating; the rest received $M$. These five textbooks all mentioned the neon light as an everyday object that illustrates the concepts of line spectra and atomic emission characteristics of certain gases. Brown et al.'s discussion of the neon light is excerpt 5.2 in Supplementary Table 2. In the chapters on quantum theory, other examples aside from neon lights are fireworks and auroras.
This study rated Zumdahl and Zumdahl (2014) as $S$ because it has long text boxes explaining the origin of certain products, such as on Post-It Notes and fireworks. While some textbooks mentioned fireworks using the same principle as neon lights (namely, that different colors of light result from unique emissions of ions), only Zumdahl and Zumdahl (2014) discussed the mechanism behind fireworks at length. Excerpt 5.1 in Supplementary Table 2 contains a part of their text box on fireworks.

\section{Chemistry Employs Instrumentation.} Relevant passages under this criterion are the discussion of specific instruments used in chemistry. Those that merited an $S$ rating are those that have extended explanations of the principles and the use of such instruments. There are three textbooks that received $S$ ratings, all of them having such rating because of the relevant text boxes. Instruments are also mentioned in the main text, but these textbooks provided additional space for explanations of certain instruments. For instance, Brown et al. (2015) has text boxes for mass spectrometry and magnetic resonance imaging; Chang (2010) has additional content on lasers and electron microscopes; and Silberberg (2009) has text boxes on mass spectrometry, basic separation techniques, and spectrophotometry. Silberberg aptly titled these text boxes as Tools of the Laboratory. A part of Silberberg's text box on mass spectrometry is cited as excerpt 6.1 in Supplementary Table 2.

Masterton et al. (2012) received $M$ because it does not have any additional text boxes, although mass spectrometry is mentioned in one passage (see Supplementary Table 2, excerpt 6.2). Hill et al. (2013), and Zumdahl and Zumdahl (2014) received $N$ ratings because discussions on specific instruments could not be found.

Chemistry Possesses Social and Societal Dimensions. Criterion 7 focuses on how science is actually practiced, how the scientific enterprise has a human and social side. The production and transmission of scientific 
knowledge are oftentimes not clear-cut and absolutely objective, but resulted from many controversies and debates. All textbooks analyzed have relevant passages pointing to some social relevance of chemistry. The excerpts under this criterion point to the human and social dimension of chemistry topics such as the relevance of studying chemistry, the scientific method, as well as short biographical notes of certain scientists. Since a short history of the atomic and quantum theories is included in all textbooks, all of them were able to discuss in various ways particular scientists in the history of chemistry. Agreeing with Vesterinen et al. (2013), anecdotal passages were given an $M$ rating. Their own results fail to see a Satisfactory and Explicit passage, saying that "portrayals of historical scientists and their work in the analyzed textbooks are mostly anecdotal and hardly provide reader with adequate descriptions of the larger cultural milieu in which scientific discoveries and innovations were made" (p. 1850).

To reach the level of an $S$ rating, this study looked for text boxes that elaborated certain social dimensions. For instance, Brown et al. (2015) has text boxes entitled Chemistry Put To Work. One such box refers to the relation of chemistry with the chemical industry, one of the desired content of Vesterinen et al. (2013) for Criterion 7. A segment of that text box is in excerpt 7.1 of Supplementary Table 2. Masterton et al. (2012), even if stating outright in their Preface that they tried to make their textbook as concise as possible, still provided text boxes that were rated satisfactory, such as Chemistry Beyond the Classroom (one on ethyl alcohol and the law, another on the changing color of lobsters when cooked) and Chemistry the Human Side (on Glenn Seaborg). Silberberg (2009), aside from text boxes (relevant ones for this criterion are titled Chemical Connections), also provided long biographical notes of certain chemists. Hill et al. (2013) has the most unique contributions with regards to Criterion 7, providing additional topics not usually discussed in standard chemistry textbooks such as risk-benefit analysis and green chemistry. They wanted their textbook to have an explicit green chemistry content and approach. All chapters in that textbook have page-long text boxes on specific aspects of green chemistry.

On the other hand, Chang (2010) and Zumdahl and Zumdahl (2014) failed to provide any additional relevant text boxes. Hence, they received $M$ ratings while the other four textbooks received $S$. Excerpt 7.2 in Supplementary Table 2 is from Chang (2010).

\section{CONCLUSIONS AND RECOMMENDATIONS}

This study aimed to formulate criteria for content analysis of general chemistry textbooks based on certain dimensions of the nature of science (NOS), informed by relevant research on NOS and history and philosophy of science (in particular, philosophy of chemistry). These criteria pertain to chemistry as being (1) tentative, (2) empirical, (3) modelbased, (4) inferential, (5) has technological products, (6) employs instrumentation, and (7) possesses social and societal dimensions. The second part of the study consisted of the application of these criteria to ascertain how and to what extent such criteria are mentioned, emphasized and elaborated in these textbooks. Despite the presence of some No Mention $(N)$ evaluations, all textbooks have mentioned some or all of the NOS dimensions formulated, resulting to $M$ and $S$ ratings. Silberberg (2009) has the highest score among the six textbooks with 12 points out of the maximum of 14. Silberberg (2009) was rated $S$ for five criteria, the most number among the six textbooks, namely: (2) empirical, (3) model-based, (4) inferential, (6) instrumentation, and (7) social and societal dimensions. Two textbooks follow closely: Brown et al. (2015) with 11 points, and Hill et al. (2013) with 10.

Originally, this study aimed at examining whether there is explicit philosophical content in general chemistry textbooks, as established by certain NOS dimensions. As the research progressed, this study faced the reality that 
such textbooks are not intended to be texts for philosophy nor philosophy of science/chemistry, and the main audience remain to be chemistry if not other science majors. (Hill et al., 2013 is an exception because it was written for non-science majors.) Thus, this study granted certain textbooks with the rating of Satisfactory and Explicit not due to explicit philosophical content, but due to additional effort on the part of the authors to move beyond the standard discussion of textbook material. These "extras" are immediately and visually seen in the form of text boxes that focus on specific chemical concepts and applications, as well as other ways of thinking about chemistry. These text boxes are considered in this study aside from the actual text.

The corresponding author worked alone in this project, a key limitation of this study. Most textbook analyses are done by more than one researcher. This is to ascertain some form of reliability in the evaluations. Published works on textbook analysis involve teams of evaluators and entailed computations of inter-rater agreements. There are deliberations as well as the quantitative measure of the inter-rater agreement between evaluators (Cohen's kappa statistic is calculated in many studies). If more than one researcher continues and improves this current study, then the inter-rater agreement could be computed. Such research would thus be more quantitative and reliable, given the increased number of evaluators.

Another recommendation is that local chemistry educators (especially those involved in chemistry education research) should look into the line of research undertaken by this thesis and examine possible applications of studies advocating for an inclusion of HPS into various forms of chemistry teaching and learning. As this is a study that promotes interdisciplinary learning between chemistry and philosophy, possible implications and applications to our K-12 program could be assessed.

\section{NOTE}

This article is a condensed version of an undergraduate chemistry thesis, bearing the same title, completed and defended by the corresponding author at the Ateneo de Manila University during the first semester of 2015, under the guidance of the three co-authors. It was then presented as a poster during the $31^{\text {st }}$ Philippine Chemistry Congress last April 1315, 2016 at Iloilo City with the theme "Chemistry Beyond Borders: Blurring Traditional Boundaries."

The author, presently a senior high school chemistry teacher at Xavier School in San Juan City, has also discovered that the said institution already uses a textbook (Pearson Baccalaureate Higher Level Chemistry, 2nd edition, by Catrin Brown and Mike Ford, ISBN 9781447959755) where text boxes on the Nature of Science (NOS) and the Theory of Knowledge (TOK) are already interspersed throughout the text. Exemplar content desired by this study is explicitly found in those text boxes. This particular textbook is published under the auspices of the International Baccalaureate Diploma Program (IBDP). Xavier School, as an IB World School, is accredited to implement the IBDP in its senior high school. Interestingly, TOK is a required separate "core" course in the IBDP, however its key concepts (as well as that of NOS) are already applied and integrated in IBDP textbooks.

\section{REFERENCES}

Brown C, Ford, M. Pearson Baccalaureate Chemistry Higher Level. 2nd ed. United Kingdom: Pearson; 2014.

Brown TL, LeMay Jr. HE, Bursten BE, Murphy CJ, Woodward PM, Stoltzfus MW. Chemistry: The Central Science. 13th ed. New Jersey: Pearson Education, Inc.; 2015.

Chang R. Chemistry. 10th ed. New York: The McGraw-Hill Companies, Inc.; 2010. 
Hill JW, McCreary TW, Kolb DK. Chemistry for Changing Times. 13th ed. (low price ed.). Jurong, Singapore: Pearson Education South Asia Pte. Ltd.; 2013.

Masterton WL, Hurley CN, Neth EJ. Chemistry: Principles and Reactions. 7th ed. California: Brooks/Cole; 2012.

Matthews MR. Science Teaching: The Role of History and Philosophy of Science. In: Nagarjuna G, editor. History and Philosophy of Science: Implications for Science Education. Mumbai: Homi Bhabha Centre for Science Education; 2001. p. 1-13.

McComas WF, Clough MP, Almazroa H. The Role and Character of the Nature of Science in Science Education. In: McComas WF, editor. The Nature of Science in Science Education: Rationales and Strategies. Dordrecht: Kluwer Academic Publishers; 1998. p. 3-39.

Niaz M. Science Textbooks: The Role of History and Philosophy of Science. In: Matthews MR, editor. International Handbook of Research in History, Philosophy and Science Teaching. Dordrecht: Springer Science+Business Media; 2014. p. 1411-1441.
Niaz M, Maza A. Nature of Science in General Chemistry Textbooks. Dordrecht: Springer; 2011.

Silberberg MS. Chemistry: The Molecular Nature of Matter and Change. 5th ed. New York: The McGraw-Hill Companies, Inc.; 2009.

Talanquer V. Chemistry Education: Ten Facets to Shape Us. Journal of Chemical Education. 2013; 90: 832-838.

Vesterinen VM, Aksela M, Lavonen J. Quantitative analysis of representations of nature of science in Nordic upper secondary school textbooks using framework of analysis based on philosophy of chemistry. Science \& Education. 2013; 22: 1839-1855.

Weisberg M, Needham P, Hendry R. Philosophy of Chemistry. Available from: http://plato.stanford.edu/entries/chemistry [Accessed 22nd Aug 2016].

Zumdahl SS, Zumdahl SA. Chemistry. 9th ed. California: Brooks/Cole; 2014. 